\title{
A FORMAÇÃO DE PROFESSORES NAS PESQUISAS NACIONAIS E ESTRANGEIRAS: TENDÊNCIAS E DESAFIOS*
}

\author{
Vanderleida R. de Freitas e Queiroz,
} do Instituto Federal de Goiás (IFG).

\begin{abstract}
RESUMO: O objetivo deste texto é discutir a formação de professores a partir da contribuição de pesquisas nacionais e estrangeiras sobre o tema. O texto mostra que há um discurso sobre a importância da formação e como esse se distancia das práticas políticas e formativas levadas a efeito. Trata, também, das tendências verificadas nas pesquisas a respeito daquilo que deve constituir um programa de formação do professor, com destaque para as questões dos saberes docentes e dos espaços formativos ideais, e como tais tendências constituem desafios a serem enfrentados tanto no âmbito das formulações de políticas e programas de formação docente como no das práticas docentes.

Palavras-chave: Formação de professores. Pesquisas. Políticas educacionais. Saberes docentes.
\end{abstract}

A educação escolar emerge como um dos problemas mais premente a ser enfrentado na contemporaneidade, diante de sua incontestável importância para a manutenção ou transformação das sociedades que a praticam. No caso da sociedade brasileira, seu estágio de desenvolvimento e as diferentes e conflituosas disputas em campo têm apontado a elevação da qualidade da formação dos sujeitos - seja para subordinação aos interesses do capital, seja para a construção de um modelo societal justo e solidário como um dos objetivos primeiros.

A efetivação de tal objetivo, sobretudo quando se pensa uma educação emancipatória e transformadora, requer professores preparados para conduzi-la e esse requisito demanda que se tome sua formação como

\footnotetext{
* Artigo recebido em 31/05/2012 e aprovado em 20/08/2012.
} 
uma das condições que precisam ser supridas. Mais do que isso: impõe que se tome a formação de professores como questão e a posicione no topo da pauta do que deve ser enfrentado com urgência. Para isso, deve-se levar em conta o que as pesquisas sobre o tema da formação docente têm demonstrado quanto às tendências observadas nas práticas formativas e às necessidades ainda não atendidas.

Tomar a formação de professores como questão é interrogar como ela tem sido materializada nos programas específicos para esse fim, visandose apreender seu sentido concreto. Estudiosos influentes, estrangeiros e nacionais, evidenciam, em suas pesquisas, as tendências que têm inspirado e marcado programas de lá e daqui, relativamente aos saberes necessários e aos espaços formativos ideais, enfatizando-se a pertinência dos saberes práticos. Ao fazê-lo, suscitam desafios que precisam ser enfrentados tanto no âmbito das políticas, quanto no das práticas pedagógicas que emergem em contextos em transformação e se concretizam nas instituições de ensino pelo conjunto de sujeitos que delas faz parte. No estudo desses pesquisadores, encontram-se duas constatações contraditórias: por um lado, a importância do professor como agente de formação dos sujeitos tem sido exaltada; por outro, a sua formação tem estado sob suspeita, desacreditada e considerada deficiente, frágil. Resolver essa contradição tem sido o esforço de governantes preocupados em alterar os resultados educacionais de seus países, a fim de alinhá-los aos padrões de qualidade mais elevados. A formação do professor constitui, pois, uma preocupação de máxima prioridade.

Entender como as tendências se apresentam, perceber suas influências nas proposições e materializações das práticas formativas de professores levadas a efeito na realidade brasileira, e compreender como tais práticas refletem o valor social atribuído ao trabalho docente diante das demandas por qualidade educacional será o esforço desta reflexão.

UMA NOTA (IM)PERTINENTE: DO DISCURSO DA IMPORTÂNCIA À IMPORTÂNCIA DA AÇÃO

As mudanças que vêm ocorrendo no mundo ocidental elevam a educação escolar ao topo das exigências que precisam ser atendidas como condição para o enfrentamento que os desafios da contemporaneidade impõem às sociedades que não desejam ficar à margem das transformações em curso, cujo horizonte é a construção da sociedade do século XXI. Isso porque se tem a compreensão, cada vez mais nítida, de que a educação escolar é uma via incontestável de "constituição de nacionalidades, realização do ser humano e das sociedades", e também "de ideários político-econômicos" 
(SOUZA, MAGALHÃES e GUIMARÃES, 2009). Em certa medida, isso explica a emergência do professor como figura da mais alta importância nesse cenário, para quem as expectativas incidem e os olhares se voltam.

Nóvoa (1999), em seu artigo intitulado Os professores na virada do milênio: do excesso dos discursos à pobreza das práticas, pondera sobre a importância atribuída ao professor nos discursos oficiais das grandes organizações, como a UNESCO, a OCDE, a União Europeia. Essas - preocupadas com a formação dos quadros profissionais necessários ao desenvolvimento, fortalecimento e à consolidação das economias dos países, bem como das gerações futuras às quais caberá conduzir a sociedade nas configurações que se desenham no mundo globalizado - tomam a figura do professor como chave para todas as transformações desejáveis e alçam-no à condição de protagonista da construção de uma nova sociedade.

O referido autor destaca:

No relatório da OCDE, Education Policy Analysis (1998), em apenas três páginas, utilizam-se expressões como: "trazer outra vez os professores para o retrato"; "colocar os professores no centro dos processos sociais e econômicos"; "os professores são os profissionais mais relevantes na construção da sociedade do futuro"; "os professores têm de voltar para o centro das estratégias culturais"; "os professores estão no coração das mudanças". (NÓVOA, 1999 , p. 14, aspas e grifos no original)

Não se pode negar a importância do professor nessa empreitada, mas considerá-lo como protagonista oculta - quando não elimina - a responsabilidade de outros atores que devem participar igualmente do projeto de construção da sociedade que se deseja. Além disso, embute-se aí uma contradição: se o discurso realça a importância do professor, negam-na as práticas políticas de formação e valorização da profissão docente.

Referindo-se à realidade europeia, Nóvoa $(1999$, p. 13) argumenta que "o excesso dos discursos esconde a pobreza das práticas políticas", evidenciando, assim, um descompasso entre o proclamado e o realizado. $\mathrm{O}$ autor afirma, ainda, que os professores, por um lado,"são bombardeados com uma retórica cada vez mais abundante que os considera elementos essenciais para a melhoria da qualidade do ensino e para o progresso social e cultural" e, por outro, "são olhados com desconfiança, acusados de serem profissionais medíocres e de terem uma formação deficiente" (NÓVOA, 1999, p. 13-14).

Se essa é a situação da realidade europeia, não será diferente no Brasil, cujas políticas educacionais, via de regra, têm-se inspirado nas dos países estrangeiros, europeus ou do hemisfério norte, a depender da "experiência formativa" dos signatários das políticas. $O$ certo é que a análise de 
Nóvoa não nos causa estranheza do ponto de vista geográfico e tampouco temporal. Embora date mais de dez anos, seu texto reflete com atualidade questões que não foram resolvidas, pelo menos aqui no Brasil, a despeito de sua defesa pelo debate das questões do presente. No nosso caso, podemos dizer que o futuro chegou ainda "pobre de presente".

Isso pode ser corroborado por pesquisas realizadas no Brasil sobre o professor e a profissionalização docente. Essa é compreendida como um processo longo e contínuo de aprendizagem da docência, que tem início antes de se ser professor e que inclui, necessariamente, além da socialização, a formação inicial e continuada (GUIMARÃES, 2006).

Estudos como os de Souza, Magalhães e Guimarães (2009), Guimarães (2004), Gatti e Barretto (2009) e Freitas (2007) demonstram o descompasso entre a valorização da profissão por meio dos discursos oficiais e aquela que se dá efetivamente nas políticas de formação e de valorização da carreira profissional de professores. De um lado, a profissão gozando de alto prestígio social, tendo sua importância reconhecida e defendida por todos os setores da sociedade; por outro, passando por um processo de desprofissionalização, considerando-se as reais condições de formação e carreira do profissional docente.

Souza, Magalhães e Guimarães (2009) - no artigo O professor na literatura educacional contemporânea: ausência ou presença alheada desenvolvem reflexão sobre essa incoerência de "mostrar-esconder", "elevarrebaixar" a figura do professor no movimento que vai do discurso à ação. Os autores observam que "[...] esse destaque ao professor se deve, sobretudo, à constatação de que ele ainda é decisivo no processo de educação do país" (p. 2). Mas, se a importância dada à educação escolar e à figura do professor pode parecer, de imediato, uma forma de "reconhecimento" do seu valor e imprescindibilidade, um olhar mais atento descobre outros efeitos não tão evidentes.

Os referidos autores analisam que, entre as razões que levam o professor a ser alvo constante de pesquisas e de atenções dos governos e da mídia, existem aquelas não declaradas, como a tentativa "de responsabilização desse profissional em relação aos destinos educativos da sociedade, [...], de controle de sua profissionalização" e servindo "muitas vezes à promoção de equipes governamentais" (p. 2).

Analisam, ainda, a partir de suas constatações, os efeitos "perversos" que demasiada atenção incide sobre a profissão docente: a) essa profissão apresenta-se como campo em disputa por exigir baixos investimentos e representar possibilidade de lucro; como via de trânsito de ideários político- 
econômicos; e sendo campo "propício para quase todo tipo de diletantismo"; b) a vulnerabilização da profissão docente se dá em razão de ser ofício antigo, extenso, importante, agregador de muitas instituições em disputa; c) o descompasso entre o discurso e ação, teoria e prática gera e alimenta "um estado de indiferença, de ceticismo do professorado, que dificulta qualquer mudança" (p. 4). Com esse quadro, o professor, nas palavras de nossos autores, só pode mesmo ser um profissional "alheado" de sua própria história.

Gatti e Barretto (2009), por sua vez, focalizam a questão da profissão docente no Brasil em como ela se encontra relativamente à empregabilidade, salários, formação, carreira, perfil socioeconômico do professorado, indicando os impasses resultantes de diversas políticas governamentais e os desafios que ainda permanecem, ou se apresentam para serem enfrentados no âmbito das políticas públicas da União, dos Estados e Municípios brasileiros.

Entre os impasses apontados pelas autoras destacam-se: as demandas por formação adequada, condizente com a legislação, são respondidas de forma diferenciada nas regiões do país e conforme o nível de ensino; os projetos de formação - de inspiração no aligeirado, emergencial, parcelado, a distância - não apontam para a superação da baixa qualidade da formação dos professores; os planos de carreira mal-estruturados, e que variam conforme a região, contribuem para a não consolidação de uma classe profissional unificada no país; salários não constituem atrativo para que os egressos mais bem sucedidos da educação básica abracem a carreira docente; a fragilidade dos cursos de licenciaturas compromete seu papel formador de professores; entre outros.

Já entre os desafios sinalizados pelas autoras estão: adoção de uma estratégia de ação articulada entre as diferentes instâncias que formam os professores e aquelas que os admitem como docentes; financiamento público condizente com a importância da profissão para o país; melhoria das perspectivas da carreira com consequente mudança do status da profissão; revisão da legislação quanto aos cursos de formação de professores, no sentido de melhor atender aos requisitos da escola, suas funções e necessidades; consideração das questões de diversidade cultural, econômica e social do país, sem descuidar do conjunto e totalidade, no tratamento com o currículo escolar.

Freitas (2007) - ao examinar as políticas e programas de formação do atual governo, em artigo intitulado $A$ (nova) política de formação de professores: a prioridade postergada - identifica vários obstáculos para efetivação de uma formação de professores sólida e de boa qualidade, ratificando as contradições delineadas. Analisa a situação atual da formação, apontando que a falta de 
uma política global de formação e a desvalorização dos profissionais - decorrentes da queda de investimento público e da precarização das condições de trabalho dos professores - geram uma contradição incontornável: jovens que poderiam trilhar os caminhos da profissão docente em universidades públicas fogem dessa carreira nada atraente; e jovens que não conseguem entrar na universidade pública são"capturados" para as universidades privadas por meio das bolsas PROUNI.

Poderíamos afirmar que tais estudantes vão formar um contingente de "professores pobres" para uma "educação pobre", para uma "população igualmente pobre". Ou, de outra forma, pode-se dizer que as políticas de formação têm resultado em ações de enfrentamento às demandas de profissionalização que se resumem em conceder bolsa para aluno pobre em escola privada em que vai se formar "pobremente". A isso, soma-se a proposta dos cursos a distância, que são pensados na lógica da aceleração do tempo, massificação, barateamento de custos ao Estado. Aplicada à formação inicial, tal medida agudiza ainda mais a questão da boa qualidade da educação, por seu caráter individualizante, solitário e aligeirado.

Os estudos desses pesquisadores permitem reconhecer a condição ambígua do professor e defender a necessidade de estudos que esclareçam e desvelem cada vez mais sua realidade. Entre as questões que carecem ser estudadas estão as relativas ao processo de profissionalização docente; à constituição de novo estatuto da profissão; às condições de ingresso e permanência na carreira por jovens estudantes; às políticas de valorização profissional; e, naturalmente, ainda e sempre, às políticas e práticas de formação inicial e continuada.

Sem reduzir todos os problemas da profissão docente à questão da formação, não se pode negar, entretanto, que essa emerge como uma das mais importantes, entre outras razões, por ser a formação um dos fundamentos da constituição de qualquer profissional. É certo que, na profissão de professor, ainda é permitido a muitos ingressar e permanecer na carreira sem experiência formativa institucionalizada, inicial ou continuada. E, não raras vezes, alguns desses permanecem sem nenhuma identificação com a profissão docente. $O$ fato de existirem professores nessas condições realça a importância da formação.

Considerando o cenário de mudanças em que se situa o professor e a necessidade de formá-lo para responder às diferentes e contraditórias demandas que se lhe apresentam, reputa-se importante refletir sobre os saberes que devem integrar um currículo de formação de professores, a partir do que as pesquisas têm indicado. Tão importante quanto investigar saberes é 
investigar espaços formativos. Por isso, continua pertinente interrogar como, quando, onde se aprende a ser professor e o que constitui o saber docente.

Esses dois conjuntos de questões encaminham o movimento discursivo que se fará a partir daqui: responder a essa problematização com os autores que oferecem contribuições para refletir sobre essas questões de um ponto de vista crítico.

A FORMAÇÃO E OS SABERES DOCENTES: INFLUÊNCIAS DOS ENFOQUES NA PRÁTICA

O conceito de formação abarca um complexo de conhecimentos relativos aos saberes requeridos para o exercício de uma profissão. No caso dos professores, tais saberes integram-se em uma rede articulada de conhecimentos científicos ou disciplinares, pedagógico-didáticos e os relacionados à cultura profissional (GUIMARÃES, 2004). Todos compõem igualmente o repertório de saberes necessários ao exercício da docência, que é, no limite, "ensinar como contribuição ao processo de humanização dos alunos historicamente situados" (PIMENTA, 2000, p. 18).

Formar o professor, sobretudo da educação básica, tem sido uma tarefa assumida pela universidade, entendida como espaço privilegiado de formação. Mesmo com programas concorrentes que primam pelo aligeiramento e expansão quantitativa, como os cursos a distância e outros congêneres, à universidade compete o histórico papel de formar os professores por meio, inicialmente, das licenciaturas.

A licenciatura constitui etapa importante de formação, ao fim do que o licenciado estará qualificado, ainda que minimamente, dentro dos rigores legais (mesmo que não tão"rigorosos" quando se trata de admitir professores que não sejam "professores") para o exercício da profissão docente. Sem entrar no mérito da questão, se a licenciatura - do modo como está estruturada e, sobretudo, da "distância" que ela mantém das Faculdades de Educação atende a requisitos formativos ideais, por ora, basta que consideremos sua importância como espaço e etapa inicial de formação.

Pimenta (2000), referindo-se à licenciatura como etapa inicial da formação de professores, afirma que o esperado é que ela

desenvolva nos alunos conhecimentos e habilidades, atitudes e valores que Ihes possibilitem permanentemente irem construindo seus saberes-fazeres docentes a partir das necessidades e desafios que o ensino como prática social lhes coloca no cotidiano. Espera-se, pois, que mobilize os conhecimentos da teoria da educação e da didática necessários à compreensão do ensino como realidade social, e que desenvolva neles a capacidade de investigar a própria atividade para, a partir dela, constituírem e transformarem os seus 
saberes-fazeres docentes, num processo contínuo de construção de suas identidades como professores. (PIMENTA, 2000, p. 18)

Este "desenho" de formação é o que, idealmente, atenderia às exigências de formação do professor para o século XXI: alguém que seja capaz de dar continuidade à sua formação a partir da própria prática, isso é, alguém que seja capaz de "interpretar" as necessidades e desafios que a atividade docente Ihe coloca cotidianamente e de dar respostas satisfatórias; empreender ações que afetem tanto o ensino - como prática social e atividade fim do professor - como sua própria identidade. É uma formação inicial que possibilite o desenvolvimento do sujeito-professor, do ensino e da própria profissão. Essa compreensão remete à questão dos conhecimentos que constituem a "necessidade epistemológica" desse ideal de professor. O que é preciso saber para assim ser capaz de atuar?

A questão enunciada evoca conceitos como "saberes-fazeres", "investigação da própria atividade", remetendo à discussão que vem sendo travada a partir de influências da produção estrangeira sobre formação de professores (SCHÖN, 2000; ELLIOT, 1998; PERRENOUD, 1993; ZEICHNER, 1998; SACRISTÁN, 2002, 1999, 1995; TARDIF, 2008, 2005, 2002; CHARLOT, 2005). Nessa produção, observam-se, entre outras, a "reflexividade" e os "saberes da prática docente" (tanto os dos professores-em-formação como os dos professores-já-professores) como "tendências" importantes que orientam as práticas de formação.

A despeito das críticas a muitas das formulações desses pesquisadores, algumas elaborações não podem ser desprezadas. A questão dos "saberes práticos" e a da capacidade de investigar a própria prática e refletir sobre ela não podem ser ignoradas nos programas formativos. Senão, como conceber um professor crítico que não reflita sobre a própria atividade e que não a investigue, no sentido de efetivar mudanças que vão desde as decisões didático-pedagógicas até aquelas que afetem sua identidade profissional? Como conceber um professor que saiba avaliar experiências e orientá-las no sentido do cumprimento de suas finalidades, sem refletir? Contudo, se reflexão e prática são conceitos importantes, igualmente importante é tomá-los criticamente, tal como nos sugere Pimenta (2002).

Referindo-se à análise que faz sobre as apropriações do conceito de reflexividade e dos enfoques na prática, a autora pontua que tal análise

coloca em evidência a indiscutível contribuição da perspectiva da reflexão no exercício da docência para a valorização da profissão docente, dos saberes dos professores, do trabalho coletivo destes e das escolas enquanto espaço 
de formação contínua. Isso porque assinala que o professor pode produzir conhecimento a partir da prática, desde que na investigação reflita intencionalmente sobre ela, problematizando os resultados obtidos com o suporte da teoria. E, portanto, como pesquisador de sua própria prática. (PIMENTA, 2002, p. 43 , sem grifos no original)

Pimenta não retira o mérito das reflexões originais sobre o conceito de reflexividade e da valorização da prática como contraponto a uma educação profissional baseada nos moldes tradicionais, em que a teoria é compreendida como normativa da prática e cuja expressão mais acabada nos currículos é o estágio ao final do processo. Mas, adverte que é preciso levar em conta o contexto das formulações originais e dos problemas aos quais elas responderam e sua contribuição na formulação das políticas de formação nos países onde foram gestadas. Traduzi-las para a realidade brasileira sem refletir sobre as condições objetivas de mudanças no âmbito das políticas de formação contraria, desde já, o princípio da reflexão.

Pontua a autora:

O ensino como prática reflexiva tem se estabelecido como uma tentativa significativa nas pesquisas em educação, apontando para a valorização dos processos de produção do saber docente a partir da prática e situando a pesquisa como instrumento de formação de professores, em que o ensino é tomado como ponto de partida e de chegada da pesquisa. Concordando com a fertilidade dessa perspectiva, cabe, no entanto, indagar: que tipo de reflexão tem sido realizada pelos professores? As reflexões incorporam um processo de consciência das implicações sociais, econômicas e políticas da atividade de ensinar? Que condições têm os professores para refletir? (PIMENTA, 2002, p. 22)

Ora, não se pode negar que a reflexão enquanto atributo do humano está presente na e sobre a ação. Contudo, é preciso que ela alcance mais do que a própria ação, vá além da dimensão individual da reflexão e alcance o caráter público e ético da mesma. É o deslocamento, sugerido por Pimenta, da "perspectiva do professor reflexivo ao intelectual crítico reflexivo" (2002, p. 43). O que se exige a esse intelectual é que seja capaz de refletir na ação e sobre a ação, considerando todas as implicações mais amplas ao ato de ensinar - como os condicionantes sociais, políticos, econômicos, culturais - e suas finalidades em uma sociedade determinada.

Quanto à ênfase na prática, percebe-se, na contribuição das pesquisas estrangeiras, clara intenção de valorização do trabalho do professor e de suas experiências efetivas como momentos significativos de construção de conhecimento. O risco dessa ênfase é o esvaziamento da dimensão teórica na 
formação docente, que é o que de fato parece ter ocorrido na "importação" das teorias estrangeiras.

Silva (2005) - ao discutir a reestruturação das licenciaturas no Brasil que se deu por exigência da implantação das Diretrizes Curriculares Nacionais para a Formação de Professores (2002/2004) - afirma que as propostas, sustentadas por um discurso que valoriza a educação e a profissionalização dos professores, não chegam nem perto de objetivarem e materializarem os discursos; ao contrário, negam-nos "cinicamente" ao apresentarem projetos e programas "aligeirados e frágeis, sob a égide da valorização da prática". A autora mostra o esvaziamento e menosprezo do e pelo conhecimento de natureza pedagógica, que tais projetos encenam em suas proposições curriculares e de organização espaço-temporal, em nome e em favor de uma formação do "professor prático reflexivo", só que sem a reflexão, porque vazia de teoria.

Pimenta (2002) ao destacar o papel da teoria relativamente à prática, defende:"O papel da teoria é oferecer aos professores perspectivas de análise para compreenderem os contextos históricos, sociais, culturais, organizacionais e de si mesmos como profissionais, nos quais se dá sua atividade docente, para neles intervir, transformando-os". E, ainda:

a teoria como cultura objetivada é importante na formação docente, uma vez que, além de seu poder formativo, dota os sujeitos de pontos de vista variados para uma ação contextualizada. Os saberes propositivos se articulam, pois, aos saberes da prática, ao mesmo tempo, ressignificando-os e sendo por eles ressignificados. (PIMENTA, 2000, p. 26)

Assim sendo, teoria e prática não podem ser dissociadas na formação inicial, sob pena de se perpetuarem condições inadequadas e insatisfatórias de formação, em que a apropriação dos conhecimentos da prática ou do "fazer" é pensada como uma etapa posterior à dos conhecimentos científicos ou de que a teoria sirva apenas para guiar a prática. O desafio decorrente dessa compreensão é levar a efeito a articulação dos saberes de natureza teórica e prática, de modo que estejam em permanente diálogo, interrogando-se mutuamente.

\section{O LÓCUS DA APRENDIZAGEM DA DOCÊNCIA: QUESTÕES DE TEORIA E PRÁTICA}

Neste tópico, recuperam-se questões relativas ao quê e onde aprender para "ser professor", ampliando a discussão sobre os saberes e os espaços de aprendizagem da docência. Considerando-se a importância da universidade como espaço de formação de professores e reafirmando-se sua primazia 
sobre os demais, convém indagar:É possível a alguém aprender a ser professor apenas cursando uma licenciatura? Ou, de outro modo: A licenciatura, como etapa inicial, tem sido um tempo e espaço satisfatórios de formação, tendo em vista os saberes necessários à aprendizagem da docência?

Formadores atentos não ignoram a insuficiência dos conhecimentos advindos apenas da "teoria" profissional (das ciências da educação, dos saberes disciplinares e curriculares) para constituírem, nesse particular, a profissionalidade docente. Além do mais, considerando-se a formação como processo contínuo, que abarca trajetórias de vida e profissional em espaços múltiplos, a formação inicial e institucionalizada, composta apenas por uma de suas etapas, não pode ser satisfatória. As questões poderiam ser reformuladas, então: Em que medida, a realidade da prática, dos contextos de trabalho, é conhecida pelos futuros professores durante sua formação e como essa realidade é (re)conhecida pelos formadores nas licenciaturas? Como os saberes da experiência que os futuros professores já possuem integram e interagem com os saberes "acadêmicos"? A quem interessam os saberes advindos das experiências prévias e contemporâneas dos alunos-já-professores? Que "utilidade acadêmica" têm esses conhecimentos? O que deve saber um professor (tanto o formador quanto o em-formação) sobre o "saber escolar"? Qual a relevância da educação institucionalizada, acadêmica, para a formação do futuro professor? Seria justo afirmar que a universidade não contempla o saber da prática que os alunos - já e futuros professores - trazem consigo, obstaculizando o diálogo da prática com "as teorias"? Estaria sendo reposto o velho e antigo problema da (in)dissociabilidade da teoria e prática?

Responder a essas questões parece ser o problema a ser resolvido no âmbito dos programas de formação. $O$ esforço para articular saberes de diferentes campos e natureza poderá levar a efetivar-se um projeto de formação inicial e continuada que promova a "interação" da universidade com a escola (entendida como a instituição de educação básica, para onde vai e atua a maioria dos professores formados pelas universidades), de modo que as práticas dos professores-já-profissionais fomentem e alimentem a produção do conhecimento sobre o saber docente. Isso tem a ver com a questão dos saberes que devem ou deveriam constituir um programa de formação de professores e do lócus de sua aprendizagem. A resposta a esse conjunto de interrogações pode ser elaborada com as contribuições das pesquisas sobre professores.

Pesquisadores estrangeiros (ZEICHNER, 1998; SACRISTÁN, 2002, 1995; TARDIF, 2002; CHARLOT, 2005) e nacionais (IRIGON, 2009; PEIXOTO, 2009; GUIMARÃES, 2009, 2004) têm demonstrado que há uma defasagem 
entre o saber da academia e o saber da prática; que aquele não responde aos desafios da prática, tornando-se, dessa forma, insuficiente ou ineficaz para o enfrentamento das questões postas ao professor no exercício da docência. Isso tem gerado certo descrédito à universidade, por não contemplar satisfatoriamente os conhecimentos que os professores constroem na e sobre a prática. Percebem-se aqui dois movimentos conflitantes: um, de negação da academia e afirmação da escola como lócus da aprendizagem da docência; outro, de suspeita da escola e afirmação da academia como lócus suficiente da aprendizagem da docência. O que nos cumpre interrogar é se a academia estaria negando os saberes da prática e com base em quê.

A negação de um saber da prática - negação verificada nas ações concretas levadas a efeito nos cursos de formação de professores, tanto no âmbito das pesquisas estrangeiras quanto das nacionais - estaria assentada nos seguintes pressupostos (nem sempre declarados ou consentidos): os professores, especialmente aqueles que atuam na escola básica, pouco sabem sobre os processos educativos, as teorias pedagógicas, as metodologias, as tecnologias etc., ainda que tenham sido "formados" na e pela universidade que os "pesquisa e critica"; o saber "legítimo" estaria na academia para onde tais professores deveriam retornar para (re)aprenderem o que precisam saber, ou que, pelo menos, permitissem "intervenções" pelos "mais entendidos". Com isso, enfatizam-se os "conhecimentos acadêmicos" - para não dizer "dos acadêmicos" - em detrimento dos "conhecimentos da prática", o que acaba por erguer barreira entre professores, instituições e saberes, ao invés de estabelecer relação cooperativa.

Como pode ser compreendida e explicada essa situação? Sem perder de vista a necessidade da crítica, poder-se-ia afirmar que, ao que parece, os pesquisadores têm insistido na importância dos conhecimentos da prática de modo a realizar o movimento de "curvatura da vara", para usar expressão de Saviani, como forma de trazer à cena aqueles conhecimentos que deveriam constituir o "alimento" da teoria. Isso porque, com Sacristán (1995, 2002), Zeichner (1998) e Charlot (2005), não se pode afirmar que os saberes profissionais, acadêmicos, não tenham importância e que só a prática pode oferecer um escopo de saber válido para a profissão docente. Mas que, sem a prática, apartada dela, não se pode construir um saber sobre a profissão, considerando sua complexidade. E a forma de se fazer isso é buscando-se a articulação entre a academia e a escola básica, em espírito de cooperação mútua, cujos interesses sejam afinados em torno de um objetivo comum: produzir conhecimentos que contribuam para elevar a qualidade do trabalho educativo. 
Sacristán (1995) e Zeichner (1998) defendem a ideia de que a prática é o lugar, por excelência, da formação. Pois é "praticando", fazendo, que os sujeitos são instigados (para não dizer obrigados) a "mobilizar conhecimentos" diversos (atenção para o caráter heterogêneo e social do conhecimento) para a realização do trabalho docente. Tomada fora de seu contexto discursivo e argumentativo, essa afirmação tem levado ao reducionismo da prática. É provável que quem nunca tenha vivenciado a realidade da escola possua limitações que não são contornadas apenas com a apropriação da teoria obtida na academia, pois essa é insuficiente para a construção do saber profissional em sua complexidade. Mas, tampouco, a prática não compreendida, não orientada por e para teoria, não articulada a ela, permite abarcar o conhecimento mais amplo da profissão.

É necessário, pois, que se tenha em vista a relação indissociável da teoria e prática. Essa prática não é a idealizada, ou somente a remota que produziu os saberes acumulados sobre a docência, mas, também, a concreta dos professores em formação. A prática construída por sujeitos reais e em situações reais não deve ser desvalorizada, subestimada, tomada como um saber de menor estatuto científico; ao contrário, deve ser confrontada com o saber acumulado, ou somada a ele para fomentar e alimentar a produção do conhecimento relativamente ao ensino.

Trazendo à discussão experiências de pesquisadores brasileiros, os achados de Guimarães (2004), em sua pesquisa sobre formação de professores - cuja base empírica foram os projetos escritos de licenciaturas da Universidade Federal de Goiás, em que buscou "discutir como eles são desenvolvidos e os desdobramentos na constituição da identidade profissional dos novos professores" (GUIMARÃES, 2004, p. 20) -, apontam para a necessidade de articulação entre os saberes teóricos e práticos. Seu trabalho permite reconhecer que, nas licenciaturas (apesar de seus avanços em busca de maior qualidade, especialmente no tocante aos conhecimentos científicos que devam prover ao futuro professor), ainda é frágil a articulação dos saberes disciplinares - derivados das ciências particulares que constituem a marca dos cursos - com os saberes pedagógico-didáticos e os relacionados à cultura profissional, os quais constituem, de fato, o escopo dos saberes profissionais do docente.

Mas, para o autor, não se trata apenas da articulação de saberes. A pesquisa evidenciou uma hierarquização entre eles, em que os conteúdos mais "importantes" são os disciplinares. Só que esses, para o autor, não são os "basilares" quando se trata de propiciar a identificação dos alunos com a profissão docente e, sim, os derivados da cultura profissional, construídos no 
exercício da docência. Esse reconhecimento leva-nos a indagar se a formação inicial permite "antecipar" as situações de ensino que os alunos vão enfrentar, especialmente aqueles que não atuam na profissão enquanto realizam seus estudos de formação inicial.

O estudo de Guimarães (2004) nos autoriza a afirmar que não é possível antecipar as situações de ensino que os alunos enfrentarão, posto que a realidade é imprevisível e carregada de conflitos de ordem diversa, principalmente em se tratando de futuro. Contudo, há que, pelo menos, propiciar o encontro com a realidade presente ao alcance dos alunos, por meio de práticas formativas que induzam o conhecimento dos fatos, o desenvolvimento de pensamento crítico e a disposição de atuar propositivamente e com ética sobre essa realidade, para sua constante transformação. Conhecer, pensar criticamente e atuar dessa forma requer aprendizado no caso, em discussão, da docência. E se é certo que a docência se aprende fazendo e relacionando-se com outros que fazem, tão certo quanto isso é a necessidade de processos formativos institucionalizados, planejados e orientados, evitando-se os espontaneísmos e os experimentalismos.

Ora, não se nasce professor, mas se faz professor. E isso, segundo Guimarães (2004), ocorre por meio de uma formação sólida, que integre conhecimentos disciplinares advindos das diversas ciências, conhecimentos pedagógico-didáticos e os relacionados à cultura profissional, derivados tanto da experiência acumulada sobre a profissão como dos sujeitos que "ensaiam" seus primeiros gestos como profissionais docentes. O autor destaca práticas formativas que permitem o compartilhamento de experiências entre estudantes-já-professores com vivência na cultura da profissão, professores em exercício pleno na profissão e estudantes que ainda não ingressaram na carreira profissional, como forma de estabelecer vínculos mais estreitos entre teoria e prática.

Planejar e desenvolver tais práticas é o desafio posto, sobretudo, para a universidade. Como afirma o autor, "ampliar o entendimento da profissão e criar novas práticas" - a discussão entre colegas sobre a atuação docente, o compartilhamento de suas dificuldades na profissão - "poderia dar mais sentido à fundamentação teórica [...]". E isso, claro, com a mediação do professor formador na discussão para evitar "maiores riscos de se resvalar para narrações lineares" (GUIMARÃES, 2004, p. 110).

A discussão sobre os saberes da prática realizada por Guimarães aponta para uma dimensão do conhecimento que não pode ser ignorada em se tratando da docência: seu caráter coletivo. O que o professor "sabe" no exercício da docência é muito do que lhe foi informado pelos outros 
professores, segundo práticas que se desenvolvem e se disseminam em dada cultura.

Sacristán (1995) contribui para essa compreensão, esclarecendo que a prática educativa deve ser entendida no conjunto de outras práticas, ao que ele denomina sistema de práticas educativas aninhadas. Desse entendimento, podem-se extrair algumas considerações: a) em toda cultura existe uma prática educativa tácita que influencia o modo de ser e fazer docente; b) o papel da cultura no processo educativo é determinante; não há prática educativa que não se dê em uma "atmosfera" cultural determinada e que dela não emane (para isso, o conceito de habitus é útil); c) o trabalho dos professores não é determinado somente pelos conhecimentos necessários para seu exercício, mas condicionado pelos sistemas educativos e pelas instituições em que eles se inserem.

Do exposto deriva que a prática educativa é definida não somente pelos professores enquanto sujeitos que gozam de autonomia para planejar, criar e executar, mas, também, em e pelos contextos diferentes onde ela se dá. Dessa maneira, a formação não deve ser um assunto de âmbito privado e de responsabilidade apenas do professor ou da universidade. Também a escola, enquanto contexto da prática, deve assumir a responsabilidade pela formação de seus professores, propiciando-Ihes condições, seja planejando e desenvolvendo práticas formativas tais como as sugeridas por Guimarães, seja permitindo a eles retornarem à universidade para continuidade de estudos.

A prática docente, conquanto seja "assunto de professor", é assunto de todos os envolvidos, com o devido respeito às atribuições de cada um. Ignorar isso é obstaculizar as mudanças que, necessariamente, dependem de ações e influências múltiplas.

O que as pesquisas revelam e a crítica realça é que mudanças estão em curso por toda parte e que, no caso brasileiro, ainda são insatisfatórias. Os pesquisadores apontam desafios que precisam ser enfrentados e decisões que precisam ser assumidas na construção de novos processos formativos de professores, tendo em conta que esses processos se movem no campo das contradições e das lutas por outra sociedade, menos injusta e menos desigual. Para isso, havemos de construir uma educação fundamentada nos ideais de emancipação, solidariedade e justiça social, assumindo a formação de professores como desafio urgente.

\section{CONSIDERAÇÕES FINAIS}

A reflexão desenvolvida até aqui evidencia que as tendências observadas - a urgência das demandas pela formação de professores frente 
aos desafios da contemporaneidade e a relevância social do trabalho docente nesse contexto - nem sempre conduzem a resultados eficazes. Tendências que não se inclinam para sua consecução. $O$ que as pesquisas estrangeiras e nacionais têm demonstrado é que há um excesso de discurso sobre o professor e sua importância e uma escassez de políticas públicas efetivas para consolidar um programa de formação docente que, realmente, alcance o contingente necessário, sem descuidar da qualidade do ensino, bem como de políticas de valorização da carreira profissional de professores.

No Brasil, as pesquisas mostram que as práticas políticas de formação de professores não têm possibilitado romper com os desafios históricos da profissionalização em que a formação esteja situada como um dos pilares mais importantes. Observa-se que, ao contrário, no afã de resgatar "a dívida" social com a formação do professor e de fazê-lo com menos custos, as políticas têm primado pelo aligeiramento dos cursos, barateamento de custos e certa mercantilização do conhecimento. Uma análise mais aprofundada pode revelar os nexos entre economia e educação e evidenciar os mecanismos que concorrem para a (in)viabilização das políticas públicas de formação.

Associadas a isso, estão as antigas questões dos saberes e suas articulações e de um currículo de formação que atenda às demandas de qualidade. A defesa que os pesquisadores nacionais têm feito aponta para a construção de novos modelos curriculares e de novas práticas formativas que promovam a articulação dos diferentes saberes em todas as instâncias de formação - inicial e continuada - e em todos os espaços - universidade e escolas -, a partir de análises críticas da realidade brasileira, levando-se em conta suas determinações e condicionantes próprios.

A questão da formação dos professores está posta, pois, como uma das questões que precisa ser enfrentada com a máxima urgência e diligência, se quisermos alcançar um futuro"rico de presente", argumentando com Nóvoa (1999) contra o postergamento das ações que são necessárias no e para o presente. Sua denúncia é da riqueza da retórica e da pobreza das ações, que têm caminhado apartadas. Isso reflete uma realidade ambígua da profissão docente: uma valorização social inquestionável e uma desvalorização profissional "incontornável", com o perdão do trocadilho.

Há carências diversas e que exigem medidas conjugadas de todos os setores responsáveis por conduzir a educação neste país, como forma de consolidar a nação nos princípios da democracia e justiça social. É bom lembrar que a educação é "obrigatória" para a constituição da cidadania, sem a qual não se tem uma nação. Desse modo, ela é obrigatória sim, mas para o Estado a quem compete prover as condições necessárias para que todo cidadão tenha direito a ela. Isso envolve equacionar desde os problemas de 
desigualdades sociais, para que todos possam ir à escola em idade adequada e nela permanecer até completar sua formação desejada, até os que se referem a conferir boa qualidade nos processos formativos, incluindo os dos professores, sem o que a educação não passará de fetiche.

THE FORMATION OF TEACHERS IN NATIONAL AND INTERNATIONAL RESEARCH: TRENDS AND CHALLENGES

ABstRACT: The purpose of this paper is to discuss teacher formation using the contribution of national and international research on the subject as a basis. The text shows that there is discussion about the importance of formation and how it distances itself from political and formative practices. It also analyzes the trends seen in research about what should constitute a teacher formation program, highlighting issues involving teachers' knowledge and ideal formative environments, and how such trends are challenges to be faced in the spheres of policy formulation, teacher formation programs and teacher practice.

KEYWORDs: Teacher formation. Research. Educational policies. Teachers' knowledge.

\section{LA FORMACIÓN DE PROFESORES EN LAS INVESTIGACIONES NACIONALES Y EXTRANJERAS: TENDENCIAS Y DESAFÍOS}

RESUMEN: El objetivo de este texto es discutir la formación de profesores partiendo de la contribución de investigaciones nacionales y extrangeras sobre el tema. El texto muestra que hay un discurso sobre la importancia de la formación y como ocurre un distanciamiento entre este y las prácticas políticas y formativas llevadas a término. También son tratadas las tendencias confirmadas en las investigaciones con respecto a aquello que debe tomar parte en un programa de formación de profesores, destacando los aspectos de los saberes docentes y de los espacios formativos ideales, y como tales tendencias se constituyen en desafíos a enfrentarse tanto en el ámbito de la formulación de políticas y programas de formación docente como en el de las prácticas docentes.

Palabras Claves: Formación de profesores. Investigaciones. Políticas educacionales. Saberes docentes.

\section{REFERÊNCIAS}

CHARLOT, B. Relação com o saber, formação de professores e globalização: questões para a educação hoje. Porto Alegre: Artmed, 2005.

DIAS-DA-SILVA, M. H. G. F. Política de formação de professores no Brasil: as ciladas da reestruturação das licenciaturas. Revista Perspectiva, Florianópolis, v. 23, n. 2, p. 381-406, jul.-dez. 2005. 
EGGERT, E. et al. Difusão da pesquisa educacional entre profissionais do ensino e círculos acadêmicos. In: Cadernos de Pesquisa, v. 35, n. 125, p. 13-35, Campinas, maioagos. 2005.

EGGERT, E.. Saberes docentes e formação profissional. Petrópolis: Vozes, 2002.

ELLIOT, J. Recolocando a pesquisa-ação em seu lugar original e próprio. Em: GERALDI, C. M. G.; FIORENTINI, D.; PEREIRA, E. M. de A. Cartografias do trabalho docente. Campinas: Mercado das Letras, 1998.

FREITAS, H. C. L. de. A (nova) política de formação de professores: a prioridade postergada. Educação e Sociedade, Campinas, vol. 28, n.100, ed. especial, p. 12031230, out. 2007.

GATTI, B. A.; BARRETTO, E, S. de S. (Coord.) Professores do Brasil: impasses e desafios. Brasília: UNESCO, 2009. (Caps. 1, 9 e 10).

GUIMARÃES, V. S. (Org.) Formação e profissão docente: cenários e propostas. Goiânia: Ed. Da PUC-Goiás, 2009.

GUIMARÃES, V. S. A socialização do profissional e a profissionalização docente: um estudo baseado no professor recém-ingresso na profissão. In: GUIMARÃES, V. S.. (Org.). Formar para o mercado ou para a autonomia? O papel da universidade. Campinas: Papirus, 2006.

GUIMARÃES, V. S. Formação de professores: saberes, identidade e profissão. Campinas: Papirus, 2004.

IRIGON, O. C. G. B. Práticas formativas, formação continuada e profissionalidade docente. In: GUIMARÃES, V.S. (Org.). Formação e profissão docente: cenários e propostas. Goiânia: Ed. Da PUC Goiás, 2009.

NÓVOA, A. Os professores na virada do milênio: do excesso dos discursos à pobreza das práticas. Revista Educação e Pesquisa. São Paulo, v. 25, n. 1, p. 11-20, jan.-jun. 1999.

PEIXOTO, E. A. M. Profissionalidade docente em educação ambiental: estudo com professores em exercício. In: GUIMARÃES, V. S. Formação e profissão docente: cenários e propostas. Goiânia: Ed. Da PUC Goiás, 2009.

PERRENOUD, P. Práticas pedagógicas, profissão docente e formação - perspectivas sociológicas. Lisboa: Dom Quixote, 1993. (Caps. 2, 7 e 10).

PIMENTA, S. G. Professor reflexivo: construindo uma crítica. In: PIMENTA, S. G. \& GHEDIN, E. (Org.). Professor reflexivo no Brasil: gênese e crítica de um conceito. São Paulo: Cortez, 2002.

PIMENTA, S. G.. (Org.). Saberes pedagógicos e atividade docente. São Paulo: Cortez, 2000.

SACRISTÁN, J. G. Tendências investigativas na formação de professores. In: PIMENTA, S. G. \& GHEDIN, E. (Org.). Professor reflexivo no Brasil: gênese e crítica de um conceito. São Paulo: Cortez, 2002. 
SACRISTÁN, J. G. A prática é institucionalizada: o contexto da ação educativa. In: Poderes Instáveis em educação. Porto Alegre: Artmed, 1999. (p. 70-98).

SACRISTÁN, J. G.. Consciência e ação sobre a prática como libertação profissional dos professores. In: NÓVOA, A. (Org.). Profissão professor. Porto: Porto Editora, 1995.

SCHÖN, D. Educando o profissional reflexivo - um novo design para o ensino e a aprendizagem. Porto Alegre: Artes Médicas, 2000. (Prefácio e Parte I, caps. I e II).

SOUZA, R. C. C. R. de; MAGALHÃES, S. M. O.; GUIMARÃES, V. O professor na literatura educacional contemporânea. Anais da 32a ANPED, 2009.

TARDIF, M. Princípios para guiar a aplicação dos programas de formação inicial para o ensino. In: EGGERT, E. et al. (Org.). Trajetórias e processos de ensinar e aprender: didática e formação de professores. Livro I. XIV ENDIPE. Porto Alegre: EDIPUCRS, 2008. p. 17-46. ZEICKNER, K. Para além da divisão entre professor-pesquisador e pesquisador acadêmico. In: GERALDI, C. M. G.; FIORENTINI, D.; PEREIRA, E. M. de A. Cartografias do trabalho docente. Campinas: Mercado das Letras, 1998.

VANDERLEIDA R. DE FREITAS E QUEIROZ é doutoranda do Programa de Pós-Graduação em Educação da Faculdade de Educação da Universidade Federal de Goiás.

E-mail: vanderleida@smail.com 